\title{
Examples for the determination of turbulent (sub-synoptic) fluxes with inverse methods
}

\author{
STEFAN EMEIS*
}

Institut für Meteorologie und Klimaforschung - Atmosphärische Umweltforschung, Forschungszentrum Karlsruhe, Garmisch-Partenkirchen, Germany

(Manuscript received August 8, 2007; in revised form December 4, 2007; accepted December 4, 2007)

\begin{abstract}
Turbulent vertical fluxes are important components of atmospheric energy and substance budgets and they play a dominant role in the surface-atmosphere exchange. Apart from high-resolution in situ measurements it is difficult to determine them. This paper, which is dedicated to Prof. Dr. Michael Hantel who recently retired, gives a short overview over existing inverse methods - experimental and numerical - to derive vertical profiles of turbulent fluxes in the atmospheric boundary layer and throughout the free atmosphere. Experimental methods comprise direct techniques and indirect parametric techniques, both using surface-based remote sensing devices. The numerical method is the budget method founded on the integration of the budget equation for the transported substance or property. This latter method has been considerably enhanced by Michael Hantel in the last 30 years; especially by developing an independent error measure. From such integration the calculation of vertical turbulent flux profiles is as well possible as the determination of aggregated surface fluxes over horizontally inhomogeneous terrain. The experimental method is most suitable for the local scale; the numerical method is more suitable for the regional and larger scales. Finally a short example for the determination of aggregated surface emission fluxes of methane from an agricultural area in Southern Germany on an intermediate scale between the local and the regional scale using a budget method combined with surface-based remote sensing of the mixing-layer height is presented.
\end{abstract}

\section{Zusammenfassung}

Turbulente vertikale Flüsse sind eine wichtige Komponente atmosphärischer Energie- und Stoffhaushalte, und sie spielen eine dominierende Rolle in den Austauschvorgängen zwischen Erdoberfläche und Atmosphäre. Außer durch hoch aufgelöste in-situ Messungen sind sie schwierig zu bestimmen. Dieser Artikel, der dem kürzlich in den Ruhestand getretenen Prof. Dr. Michael Hantel gewidmet ist, gibt einen kurzen Überblick über existierende inverse Methoden - sowohl messtechnische wie numerische - um vertikale Profile von turbulenten Flüssen in der Grenzschicht und in der gesamten freien Atmosphäre abzuleiten. Die messtechnischen Methoden umfassen direkte und indirekte parametrisierende Verfahren, die beide auf bodengestützten Fernmessungen beruhen. Die numerische Methode ist die Haushaltsmethode, die auf der Integration der Haushaltsgleichung für die transportierte Substanz oder Eigenschaft basiert. Diese letztere Methode ist durch Michael Hantel in den letzten 30 Jahren entscheidend erweitert worden, insbesondere durch die Möglichkeit der Bestimmung eines unabhängigen Fehlermaßes. Mittels solcher Integrationen sind sowohl die Berechnung vertikaler Flussprofile wie auch die Bestimmung räumlich gemittelter Oberflächenflüsse über horizontal inhomogenem Gelände möglich. Die messtechnische Methode eignet sich am besten für kleinskalige Anwendungen während die numerische Methode für Anwendungen auf regionalen und größeren Skalen besser ist. Abschließend wird ein kurzes Beispiel für die Bestimmung eines räumlich gemittelten Methanemissionflusses aus einem landwirtschaftlich genutzten Gebiet Süddeutschlands vorgestellt. Dieser wird auf einer intermediären Skala zwischen der kleinen und der regionalen Skala unter Benutzung einer Kombination aus Haushaltsmethode und bodengestützten Fernmessungen der Mischungsschichthöhe bestimmt.

\section{Introduction}

This paper is dedicated to Prof. Dr. Michael Hantel, Chief-Editor of Meteorologische Zeitschrift from 2000 2006, who recently retired from the chair of Meteorology at Vienna University.

The differentiation of an atmospheric property in a mean and a fluctuation usually implies that the mean describes the main part and that the fluctuation is only

\footnotetext{
*Author's address: Stefan Emeis, Institut für Meteorologie und Klimaforschung - Atmosphärische Umweltforschung - Forschungszentrum Karlsruhe GmbH, Kreuzeckbahnstr. 19, 82467 GarmischPartenkirchen, Germany, e-mail: Stefan.Emeis@imk.fzk.de
}

a minor correction to the mean. This is probably true for most physical variables, but not for vertical fluxes in the shallow Earth's atmosphere. Mean vertical fluxes on the global scale are limited because here the flatness and the overall static stability of the atmosphere are essential. Vertical fluxes in the atmospheric boundary layer are limited due to the proximity of the solid surface. In both cases, turbulent vertical fluxes driven by shear and convection are dominating over mean vertical fluxes. On synoptic scales up to global scales these turbulent fluxes are sometimes (and also in this paper) named subsynoptic fluxes (see e.g. HANTEL, 1987), in the boundary layer they are usually called turbulent fluxes. 
Let $e$ be an atmospheric property and $\vec{v}$ the vector of the three-dimensional motion, and let us denote the mean quantity by an overbar $\overline{()}$ and the deviation from this mean by a prime ('). Then $\bar{e} \overline{\vec{v}}$ is the mean flux of the property $e$ and $\overrightarrow{e^{\prime} \vec{v}}$ the turbulent (sub-synoptic) flux of this property. The actual flux of the property e therefore is the sum out of two parts:

$$
e \vec{v}=\bar{e} \overline{\vec{v}}+\overline{e^{\prime} \vec{v}}
$$

Thus, in areas where mean vertical motions are negligible vertical transports of any property are completely governed by turbulent fluxes of this property. Wellknown examples are the vertical energy fluxes away from the Earth's surface which close the energy balance of this surface. These fluxes are pure turbulent fluxes. Thus any complete study of the surface energy budget requires the determination of turbulent fluxes. The same applies to the global energetics where sub-synoptic vertical fluxes play an important role (see e.g. LORENZ (1967) and HAIMBERGER and HANTEL (2000)).

The consideration and determination of turbulent fluxes is now about 100 years old. TAYLOR (1915) firstly treated the problem of turbulent heat transport in the atmosphere. He introduced an eddy conductivity because it appeared to him that heat is transported upwards through the atmosphere by means of eddies in the same way as heat is transmitted in a solid body with a given conductivity. SCHMIDT (1921), however, postulated that the turbulent heat flux is directed downwards. He considered fluctuations of the vertical wind that are zero in the mean and adiabatic temperature changes of air parcels which are forced through a fixed horizontal surface by these fluctuations. The parcels had no temperature deviation from the mean stratification before being moved by the vertical wind fluctuations. Only if the stratification is unstable it is possible to transport heat upward by turbulent motion this way. This incomplete view of the turbulent flux only considers mechanical turbulence. It was not before 1942 that the theoretical meteorologist Ertel (for an English translation of the most important pieces of his impressing work see SCHUBERT et al., 2004) finally showed that the turbulent flux must be directed upward in the mean. He argued that frequently heat fluctuations are responsible for vertical wind fluctuations (thermally-induced or convective turbulence) and therefore rising particles are already warmer and sinking particles are already colder than their environment.

RIEHL and MALKUS (1958) introduced a new view on this issue. They looked at the heat budget of the inner tropical convergence zone and concluded that there must be an upward directed turbulent heat flux, because the flux due to the mean mass circulation does not transport as much heat upward as is transported to the poles aloft. They estimated that in a $10^{\circ}$-wide belt along the equator 1500 to 5000 huge "hot tower" (i.e. giant cumulonimbus clouds) must be active in order to maintain this turbulent heat flux. This appears to be the first time that the turbulent heat flux had been determined from largescale data as a residual. The consideration of this idea is continued later in section 3 of this paper.

Following the direct approach as expressed by Eq. (1.1), the determination of a vertical turbulent flux implies the measurements of both the vertical velocity fluctuations and the density fluctuations of the property in question with equally high temporal resolution. Today this is no problem for point or in-situ measurements near the ground where high-resolution instruments can be operated. But how can these fluxes be determined in layers higher above the ground where the operation of in situ-instruments is not routinely possible? So far, for logistic and financial reasons, aircraft operations are not suitable for operational measurements. And a second important question arises: how can horizontally varying turbulent fluxes be aggregated for larger areas up to the global scale for global energy budgets?

This paper addresses some developments in determining turbulent vertical fluxes in the atmosphere in the recent decades. While measurements of fluxes are suitable for local scales they cannot be employed for the determination of fluxes and their profiles on regional and larger scales up to the global scale. Therefore two major lines will be presented. Both of them are indirect methods because they involve some sort of an inversion procedure. One way of determining vertical flux profiles, suitable for the local scale, is the usage of remote sensing techniques. Remote sensing is thereby an indirect method like nearly all other in situ measurement techniques except simple length, weight, and time measurements. The other approach, suitable for the regional and any larger scale, is to compute them as residuals from an otherwise complete large-scale budget of the property in question. In both lines remarkable developments have occurred in the last forty years. We will start with a short overview on remote sensing techniques and then turn to the residual techniques. Finally we will show how a modification of the residual technique together with the employment of remote sensing instruments can be used also to determine horizontally aggregated surface fluxes on an intermediate scale between the local and the regional scale.

\section{The remote sensing technique}

Remote sensing delivers the measured variables only after an inversion procedure has been applied to the received signal. In this inversion the received information has to be converted using the modifications in frequency, intensity, and polarisation between the emitted radiation and the one received by the remote sensing instrument. 
A recent review on the abilities of active remote sensing in measuring turbulent fluxes of heat and momentum has been published by ENGELBART et al. (2007). Two principal methods for the determination of fluxes from remote sensing can be imagined. The first one, called 'direct method', determines the wind fluctuations and the fluctuations of the transported property simultaneously in the same volume of air. This method is 'direct' in the sense that it tries to determine the fluctuations needed in (1.1) separately although it remains an indirect measurement method due to the inherent nature of nearly any measurement technique as mentioned above. The second method, the 'parametric method', measures mean wind and property profiles and then derives the turbulent fluxes from a parameterisation (STULL (1988) with further references). Airborne and space-based remote sensing methods to determine surface fluxes and methods using scintillometers will not be considered in this paper, because it will concentrate on the use of budget methods, the main subject of Michael Hantel's work.

\subsection{Direct methods}

None of the remote sensing techniques such as sodar (GILMAN et al., 1946; Peters, 1991), windprofiling radar (GOSSARD, 1990), and lidar (FIOCCO and SMULLIN, 1963) is able to measure directly the turbulent fluxes of sensible or latent heat with one single instrument. Therefore always two different instruments have to be operated simultaneously. In particular, the measurement of humidity fluxes (which was not covered in ENGELBART et al. (2007)) requires the lidar technique for the detection of moisture fluctuations and a second remote sensing instrument for the determination of vertical wind fluctuations (see section 2.1.1 below). Attempts to use just one coherent DIAL to measure both the moisture and the wind fluctuations were not successful because it was not possible to reach meaningful signal-to-noise ratios for the wind fluctuations and the moisture fluctuations simultaneously (BÖSENBERG, 2005). However, with a RASS (MARSHALL et al., 1972) it is possible to measure sensible heat fluxes with one single instrument (see section 2.1.2 below).

\subsubsection{Moisture fluxes}

A first attempt to measure remotely the moisture flux with surface-based instrumentation was described in SENFF et al. (1994). They used a differential absorption lidar (DIAL) to measure the water vapour fluctuations from the water vapour absorption line around $729 \mathrm{~nm}$ and a radar-based radio-acoustic sounding system (radar-RASS) with a centre frequency of $1235 \mathrm{MHz}$ to measure the vertical wind fluctuations. From a combined evaluation of both datasets the turbulent vertical moisture flux was determined between $400 \mathrm{~m}$ (lower range of the DIAL) and $700 \mathrm{~m}$ (upper range of the radar-RASS) above ground. WULFMEYER (1999b) further advanced this by development and application of a DIAL system with lower noise and systematic errors (WULFMEYER 1998; WULFMEYER, 1999a). They achieved an improvement by about a factor of 4 in accuracy.

GIEZ et al. (1999) used a DIAL and a Doppler-lidar to obtain turbulent latent heat fluxes between 500 and $1200 \mathrm{~m}$ above ground. The Doppler-lidar used a $\mathrm{CO}_{2}$ pulsed gas laser emitting at a wavelength of $10.59 \mu \mathrm{m}$. The backscatter was mainly from aerosol particles with a radius of 1 to $3 \mu \mathrm{m}$. These aerosol particles are small enough to follow the turbulent fluctuations of the wind field. If weather conditions are favorable, the range of this technique can be extended up to $2000 \mathrm{~m}$ above ground (LiNNÉ et al., 2007). They used two DIAL systems, one based on a Alexandrite laser (WULFMEYER, 1998) and one based on a Ti:sapphire laser (ERTEL, 2004), and a Doppler-lidar with heterodyne detection at $1120 \mathrm{~nm}$. Additionally, they made a comparison between their technique and the technique using a DIAL and a radar-RASS and they found comparable results within the height range in which both techniques were operating. The employment of a Doppler-lidar seems to be the more convenient approach compared to a radarRASS because this technique permits the detection of the latent heat flux profile throughout the whole boundary layer even in the daytime convective boundary layer.

A third approach was made by RAO et al. (2002). They tried the combination of a Raman lidar and a sodar for the determination of the vertical latent heat flux profile. They only reached a few hundred metres above the ground and the error in the fluxes was at least $50 \%$ so that they could only derive some qualitative information on these fluxes in shallow nocturnal boundary layers.

\subsubsection{Sensible heat fluxes}

A remote sensing method of a direct measurement of vertical heat flux profiles was at first suggested in PETERS et al. (1985) using a sodar/RASS. The height range is limited by the RASS component of the instrument and is the order of 500 to $800 \mathrm{~m}$. Early applications were performed by ANGEVINE et al. (1993a, b). Recent measurements were documented in ENGELBART and BANGE (2002) and VogT and ENGELBART (2002). The first of these two papers also introduces the theoretical background. The trial to design a momentum flux measurement method for a single device by using the spaced-antenna drift (SAD) method has not yielded the desired success yet (HIRSCH, 2002). Further details can be found in ENGELBART et al. (2007). 


\subsection{Parametric methods}

The preceding two subchapters have shown that the availability of direct methods for the remote sensing of turbulent fluxes is limited. Therefore studies on the applicability of parametric methods have been made. Basically, turbulent fluxes $\overline{e^{\prime} w^{\prime}}$ are derived from the mean vertical profiles of the property e invoking (often empirical) flux-gradient relationships:

$$
\overline{w^{\prime} e^{\prime}}=-K_{e} \frac{\partial \bar{e}}{\partial z}
$$

The difficult task is now shifted from the measurement of the fluctuations of the property e to the determination of the exchange coefficient $K_{e}$.

As an example for this difficulty, the turbulent exchange coefficient for momentum $K_{m}$ could formally be estimated from the ratio of the turbulent momentum flux and the mean vertical wind speed gradient by inverting the flux-gradient relationship (2.1). But often only the mean wind gradient is easily available. About the unknown turbulent momentum flux it is only known that it is in some way (STULL, 1988) related to the variance of the vertical velocity component. Thus, using surfacebased remote sensing $K_{e}$ could be derived from sodar data which deliver mean wind profiles and mean profiles of the variance of the vertical wind component. EMEIS (2004) has compared vertical profiles of the turbulent exchange coefficient over mountainous and flat terrain using a height-dependent ratio between momentum flux and the variance from literature data (STULL, 1988). KouZnETSOV et al. (2007) investigated the ratio between momentum flux and variance in more detail and derived an empirical function for this ratio which depends on the flux Richardson number.

Another example for attempts to measure the vertical turbulent latent heat flux employing the parametric method is described in KIEMLE et al. (1997) and WULFMEYER (1999b). They operated airborne and ground-based DIAL systems, respectively, to derive the flux from measured mixing ratio gradients and variance profiles.

\section{The residual technique}

The other possibility to estimate vertical turbulent (or subsynoptic) fluxes, is to follow the idea of RIEHL and MALKUS (1958) and to analyse their effects on the larger (e.g. the synoptic) scale. This method is probably the only advisable method for regional and larger scales. This requires reliable data in order to avoid that the signal is blurred by noise due to measurement and subsequent analysis errors. In employing such a residual method it is important that the order of magnitude of the errors can be determined; only when the signal is clearly above the noise level it can be interpreted quantitatively and reliably. An objective error estimate is therefore mandatory for any serious residual method.

Basis of all residual techniques is the continuity equation for an atmospheric property e that has sources $\mathrm{Q}$ and/or sinks $\mathrm{R}$ in the volume of interest $\mathrm{V}$.

$$
\int_{V} \frac{\partial e}{\partial t} d V=-\int_{V} \nabla e \vec{v} \cdot d V+\int_{V} Q \cdot d V-\int_{V} R \cdot d V
$$

By the virtue of the Gauss theorem the first volume integral on the right-hand side of (3.1) can be replaced by an integral over the surface $\mathrm{S}$ surrounding this volume $\left(v_{n}\right.$ is the velocity component perpendicular to this surface).

$$
\int_{V} \nabla e \vec{v} \cdot d V=\int_{S} e v_{n} \cdot d S
$$

Following (1.1) we can rewrite the right-hand side of (3.2). Hereby we imply that the spatial dimensions over which the integrals are computed are much larger than the spatial scale designed by the overbar.

$$
\int_{S} e v_{n} \cdot d S=\int_{S} \bar{e} \cdot \bar{v}_{n} \cdot d S+\int_{S} \overline{e^{\prime} v_{n}^{\prime}} \cdot d S
$$

Putting (3.1) to (3.3) together we can solve for the integral over the turbulent fluxes $\overline{e^{\prime} v_{n}^{\prime}}$ through the surface enclosing the volume of interest:

$$
\begin{aligned}
& \int_{S}^{\overline{e^{\prime} v_{n}^{\prime}}} \cdot d S= \\
& -\int_{V} \frac{\partial e}{\partial t} d V-\int_{S} \bar{e} \cdot \bar{v}_{n} \cdot d S \\
& +\int_{V} Q \cdot d V-\int_{V} R \cdot d V
\end{aligned}
$$

Neglecting horizontal turbulent fluxes, which are usually much smaller than their respective mean fluxes, denoting the vertical wind component by $\mathrm{w}$ and introducing a surface flux $\overline{e^{\prime} w_{\text {surf }}^{\prime}}$ and an unknown term imb (called imbalance), which contains all measurement errors, we get for the vertical turbulent flux through the horizontal surface $S_{1}$ at the top of the volume $V$ :

$$
\begin{aligned}
& \int_{S_{1}} \overline{e^{\prime} w^{\prime}} \cdot d S= \\
& -\int_{V} \frac{\partial e}{\partial t} d V-\int_{S} \bar{e} \cdot \bar{v}_{n} \cdot d S-\int_{S_{\text {surf }}} \overline{e^{\prime} w^{\prime}} \cdot d S \\
& +\int_{V} Q \cdot d V-\int_{V} R \cdot d V-\int_{i m b} \cdot d V
\end{aligned}
$$

We will now apply (3.5) in two different ways. One will be the derivation of vertical flux profiles, the other will be the aggregation of horizontally inhomogeneous surface fluxes. 

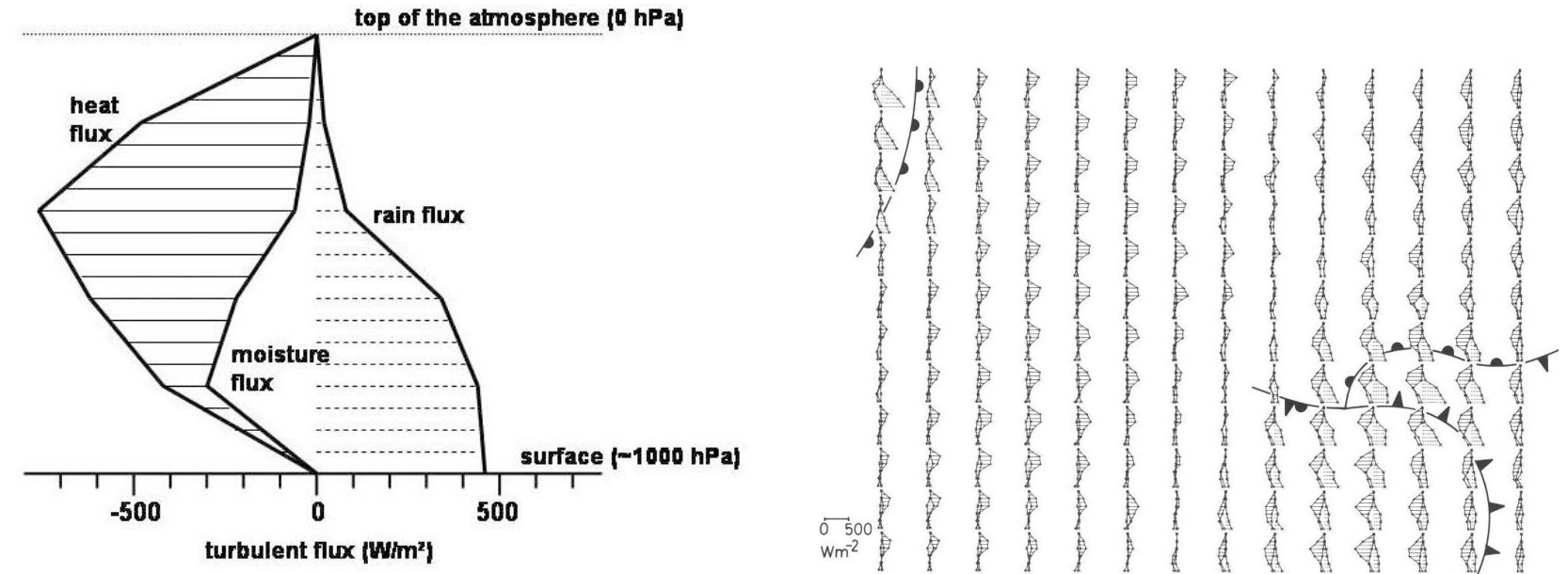

Figure 1: left: Typical vertical profiles of turbulent (subsynoptic) heat $\left(\mathrm{c}_{p} \mathrm{~T}\right)$, moisture (Lq), and rain (LP) fluxes in W/m² between the Earth's surface and the top of the atmosphere. Vertical resolution: $200 \mathrm{hPa}$. (adapted from EMEIS, 1986). Right: Vertical profiles of turbulent fluxes of latent heat, sensible heat, and precipitation for 168 columns over Europe (from EMEIS, 1986).

\subsection{Determination of vertical flux profiles}

Applying (3.5) for several layers one above the other and starting with a known or prescribed surface flux value in the lowest layer allows the derivation of vertical profiles of the turbulent flux. Please note that in (3.5) $S_{1}$ and $S_{\text {surf }}$ denote the upper and the lower surfaces of $\mathrm{V}$ whereas $\mathrm{S}$ comprises all, horizontal and vertical, surfaces of the volume V.

PALMÉN (1966) gave a first vertical profile of the turbulent heat flux for the whole troposphere north of $32^{\circ} \mathrm{N}$ and speculated which process would be dominating, the synoptic-scale or the small-scale turbulence. The profile was estimated from given horizontal heat fluxes at $32^{\circ} \mathrm{N}$ (second term on the right-hand side of (3.5)) along with vertical distributions of the radiation flux divergence and condensation (fourth and fifth term on the right-hand side of (3.5)), and a surface flux (third term on the righthand side of (3.5)). He ended up with about $40 \mathrm{~W} \mathrm{~m}^{-2}$ at the ground. An imbalance was not considered by him so that all errors were contained in the vertical flux. The flux he found became smaller with height and vanished at the tropopause. Palmén's method was also used by YANAI et al. (1973) in order to determine the processes in tropical cloud clusters. For a $6.2 \cdot 10^{11} \mathrm{~m}^{2}$ wide area over the Marshall Islands they determined vertical profiles for the vertical turbulent fluxes of dry $\left(c_{p} \mathrm{~T}+\mathrm{gz}\right.$, $c_{p}$ : specific heat for constant pressure, $\mathrm{T}$ : temperature, $\mathrm{g}$ : gravity acceleration, and $\mathrm{z}$ : height above sea level) and moist static energy $\left(c_{p} \mathrm{~T}+\mathrm{gz}+\mathrm{Lq}, \mathrm{L}\right.$ : heat of condensation, q: absolute moisture) and for the apparent heat and moisture sources (principally the sum over the first and second term on the right-hand side of (3.5)). They found the maximum flux at about $700 \mathrm{hPa}\left(200 \mathrm{~W} \mathrm{~m}^{-2}\right)$, a slight minimum around $900 \mathrm{hPa}\left(180 \mathrm{~W} \mathrm{~m}^{-2}\right)$ and a surface value of $189 \mathrm{~W} \mathrm{~m}^{-2}$. Above $700 \mathrm{hPa}$ they found linearly decreasing values and the flux vanished at about $100 \mathrm{hPa}$.

The application of (3.5) for the vertical turbulent moist static energy flux with a consideration of the imbalance imb was first made by HANTEL (1976). The vertical integral over a whole atmospheric column of (3.5) is independent of the vertical turbulent flux within this column. In a first step, this allows the specification of imb from observed large-scale data once a value or at least a first guess for the surface flux is available. The resulting imbalance was then redistributed equally within the vertical in order to calculate the vertical profile of the turbulent flux. Calculated vertical fluxes divergences were only considered to be significant when they were larger than the imbalance.

In HANTEL (1976), the atmosphere was divided in four latitudinal belts each of which was divided into four slices in the vertical. By using constant intervals of the sine of latitude as horizontal coordinate and of pressure as vertical coordinate 16 volumes of equal atmospheric mass were defined. This procedure delivered four vertical profiles of vertical turbulent flux of moist static energy. HACKER (1981) refined the scheme by dividing each latitude belt into 12 sections and computed seasonal means of the 48 vertical profiles of moist static energy and the apparent moisture source.

Later Emeis (EMEIS and HANTEL, 1984; HANTEL and EMEIS, 1985; EMEIS, 1985, 1986) further enhanced the scheme and left the hemispheric approach. In these papers, a system of 16 by 16 columns over Europe was considered. Each of the about 150 by $150 \mathrm{~km}$ wide columns was divided in the vertical into five $200 \mathrm{hPa}$ deep boxes. In this system, the vertical turbulent (subsynoptic) fluxes of enthalpy cpT, moisture Lq, and precipitation LP, (P: rate of precipitation) were calculated from synoptic data. The column imbalance for moisture 


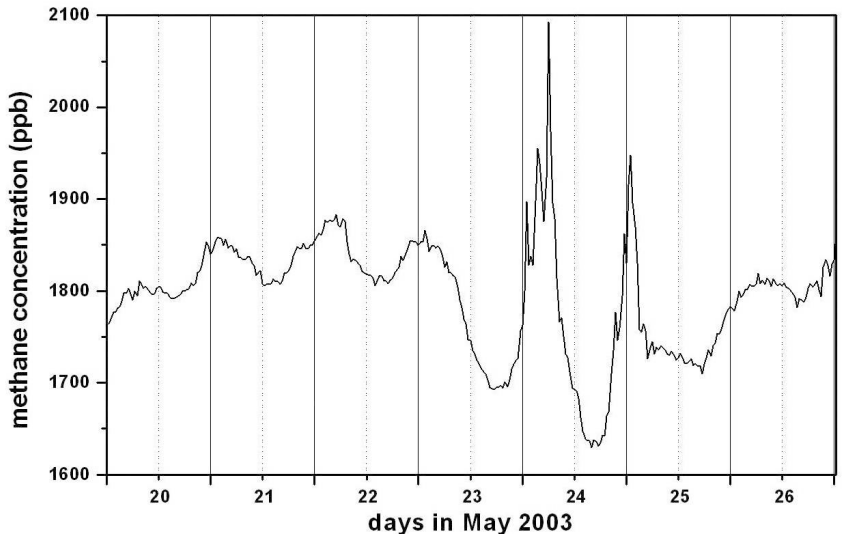

Figure 2: Variation of the near-surface concentration of methane (in $\mathrm{ppb}$ ) in a rural area west of Munich during the week from May 20 to May 26, 2003.

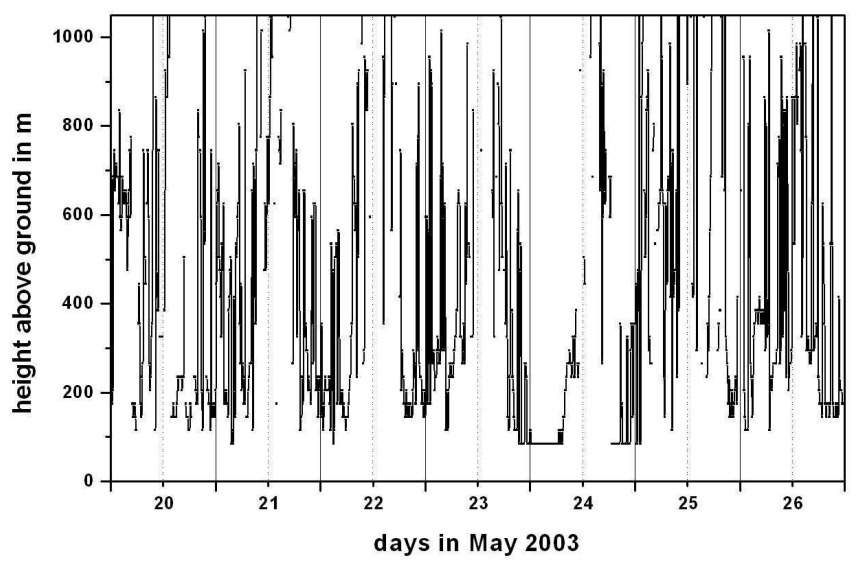

Figure 3: As Fig. 2, but for the mixing-layer height derived from surface-based acoustic remote sensing (in $\mathrm{m}$ ).

was re-distributed in the vertical in accordance to the mean moisture content in each box while the enthalpy imbalance was re-distributed equally as in the aforementioned studies. Main results of this study were that the imbalance for the computation of the vertical turbulent enthalpy fluxes was less than those for the vertical turbulent fluxes of dry static energy, and that the vertical flux profiles showed a clear relationship to the synoptic situation (see Fig. 1). An even further refinement into 24 by 24 by 10 boxes $(100 \mathrm{~km}$ by $100 \mathrm{~km}$ by $100 \mathrm{hPa})$ was performed by HANTEL (1987). Finally the successful scheme became known as the analyse scheme DIAMOD (HANTEL et al., 2001). The computation of separate enthalpy (w(z)) and moisture fluxes (f(z)) in DIAMOD requires as a closure the specification of a vertical profile of the Bowen ratio $\beta(\mathrm{z})=\mathrm{w}(\mathrm{z}) / \mathrm{f}(\mathrm{z})$. The sum of $\mathrm{w}(\mathrm{z})$ and $\mathrm{f}(\mathrm{z})$ is the convective flux $\mathrm{c}(\mathrm{z})$. c ( $\mathrm{z})$ often vanishes at the top of the atmospheric boundary layer.

In a final paper, HANTEL and STEINHEIMER (2006) analysed the vertical profiles of $\mathrm{c}(\mathrm{z}), \mathrm{w}(\mathrm{z})$, and $\mathrm{f}(\mathrm{z})$ within the atmospheric boundary layer and the possible problems which could arise within DIAMOD if $\mathrm{c}(\mathrm{z})$ vanishes and the choice of $\beta$ in this height becomes very important. Several choices of $\beta$-profiles are possible and reasonable, a final decision can only be made from separate measurements of the fluxes $\mathrm{w}(\mathrm{z})$ and $\mathrm{f}(\mathrm{z})$. This paper concludes a thirty year period within which Hantel and his co-workers, which had been inspired by him, have developed a powerful and reliable diagnostic tool for regional-scale vertical energy flux profiles out of a global energy budget scheme.

\subsection{Determination of spatially aggregated surface fluxes}

Equation (3.5) can be evaluated in a different way, too (DENMEAD et al., 1996, 2000). Imagine an atmospheric boundary layer over an area with inhomogeneous land use patterns, which is covered by a thermal inversion that suppresses all turbulent motions at the height of the inversion. In this case, the left-hand side of (3.5) would be zero. If we further assume that horizontal advection can be neglected, then the second term on the right-hand side of (3.5) vanishes, too. The same applies to the fourth and the fifth term on the right-hand side if we stipulate the absence of any sources and sinks within the boundary-layer air. We then get:

$$
\int_{S_{\text {surf }}} \overline{e^{\prime} w^{\prime}} \cdot d S=-\int_{V} \frac{\partial e}{\partial t} d V-\int i m b \cdot d V
$$

This means that a spatially aggregated surface flux of a property $e$ into the atmospheric boundary layer can be determined from the increase of the density of $e$ within the boundary-layer air in a volume $V=S_{\text {surf }} \cdot z$ if the boundary layer is horizontally homogeneous in the respect that horizontal advection is negligible and if it is covered by an inversion in a known height $z$. Unfortunately, the simple way to estimate the imbalance as it has been available for Eq. (3.5) (an integration over the whole column from the ground to the top of the atmosphere) is not feasible here. The imbalance in Eq. (3.6) is given by the measurement errors for the density of the property e and the height of the volume $\mathrm{z}$, and the correctness of the assumption of negligible horizontal advection.

An example for the application of (3.6) is given in Figures 2 to 4. It is taken from data from a measurement campaign from 13 to 30 May 2003 which took place west of Munich, Germany. In contrast to DENMEAD et al. $(1996,2000)$, in the dataset used here the most important parameter in (3.6), the mixing-layer height, is known continuously at one location from surface-based acoustic remote sensing with a sodar (for details of the mixing-layer height algorithm see EMEIS and TÜRK, 2004). Fig. 2 shows a part of the time series of the near surface concentration of methane measured at Maisach 


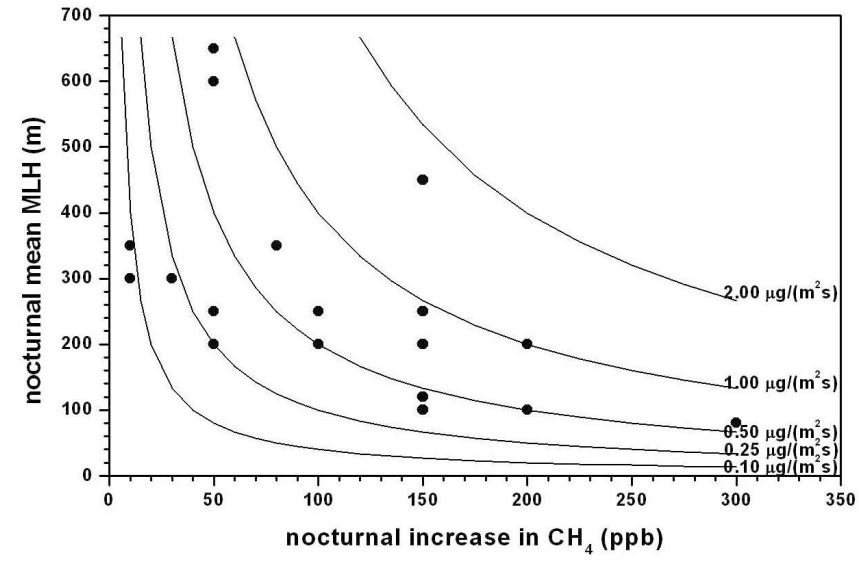

Figure 4: Correlation between the nocturnal increase of the nearsurface methane concentration ( $\mathrm{x}$ axis, in $\mathrm{ppb}$ ) and the nocturnal mean mixing-layer height (y-axis, in $\mathrm{m}$ ) in a rural area west of $\mathrm{Mu}$ nich for 18 nights between May 13 and May 30, 2003 (dots). Curves give mean emission rates for constant conditions over about eight hours.

west of Munich. It is remarkable in this time series that the concentration always increased in the evening and in the night and that it then decreased again during the next day. This nocturnal increase was largest in the nights to May 24 and May 25. Fig. 3 displays the variation of the mixing layer height derived from sodar data (hourly values) for the same time period. The sodar was operated only about two kilometres away from the site where the methane concentration was recorded. In the nights to May 24 and 25 the mixing-layer heights took their lowest values and remained at these low values for six (May 25) to twelve (May 24) hours.

If we now assume that the methane concentrations are equally dispersed within the shallow nocturnal boundary layer and that the measured mixing-layer height is representative for the region, we can use (3.6) to convert the measured methane concentrations into spatially aggregated surface methane emission rates. The result is displayed in Fig. 4 for the whole measurement period of two weeks. A mean mixing-layer height for each night has been derived from the data shown in Fig. 3 and has been related to the mean nocturnal rate of increase in the methane concentration. The array of hyperbolae in Fig. 4 indicates emission rates which would explain the assumed correlation between the concentration increase and the mixing-layer height if the adopted conditions would last for about eight hours. It turns out that most data points lie between 0.1 and $1 \mu \mathrm{g} /\left(\mathrm{m}^{2} \mathrm{~s}\right)$. If one assumes that vertical mixing takes place within one hour (from the definition of the term mixing-layer adopted in SEIBERT et al. 2000) then moderate horizontal winds of 3 to $5 \mathrm{~m} / \mathrm{s}$ would lead to horizontal transports of 11 to $18 \mathrm{~km}$ during this hour. From this estimation it can be inferred that emission rates calculated with this boundary-layer budget scheme are representative for an area of about 15 by $15 \mathrm{~km}^{2}$.

The emission rate of 0.1 to $1 \mu \mathrm{g} /\left(\mathrm{m}^{2} \mathrm{~s}\right)$ can be compared to the total methane emissions in the Federal Republic of Germany which is $2.2 \cdot 10^{18} \mu \mathrm{g}$ per year (UBA, 2007). Normalized to the area of $3.57 \cdot 10^{11} \mathrm{~m}^{2}$ this results in an average German methane emission rate of $0.2 \mu \mathrm{g} /\left(\mathrm{m}^{2} \mathrm{~s}\right)$. Two thirds of these emissions (UBA, 2007) are supposed to be from the agricultural sector (i.e. $\left.0.13 \mu \mathrm{g} /\left(\mathrm{m}^{2} \mathrm{~s}\right)\right)$. Since the measurements above have been made in a predominantly agricultural area, values a bit higher than the national average agricultural emission rate, as displayed in Fig. 4, can be regarded as realistic.

\section{Conclusions and outlook}

In-situ measurements of turbulent quantities and fluxes in the free atmosphere are difficult. Therefore other methods had to be developed to monitor the turbulent fluxes of energy, moisture, momentum, and trace substances throughout the whole height of the atmosphere. Naturally, these methods are indirect ones based on some sort of inversion algorithms. Here, a short look on the status of surface-based remote sensing of turbulent energy fluxes has been given in chapter 2, and two types of residual techniques (or budget methods) have been presented in chapter 3 . The remote sensing technique is most suitable for a local-scale flux determination. The residual techniques are probably the only advisable technique to derive these fluxes on regional and larger scales up to the global scale.

It is an important task in the future to merge these techniques, e.g. by the development and application of scanning remote sensing systems and by comparisons of their results with residual techniques. The state of the art of the presented inverse techniques let it seem possible that advantages could result from a combined use of residual techniques and surface-based remote sensing for scales between the local and the regional scale with a spatial resolution of about 10 to $20 \mathrm{~km}$. For the task of determining vertical profiles of turbulent fluxes throughout the whole atmosphere surface-based remote measurements of these fluxes within the atmospheric boundary-layer can complement profiles obtained for the whole depth of the atmosphere with budget schemes like DIAMOD described in section 3.1. Likewise, remote sensing of the mixing-layer height can deliver the most important parameter which is needed to apply successfully the nocturnal boundary-layer budget method addressed in section 3.2.

Further, surface-based remote sensing could deliver estimates of the fluxes of enthalpy and moisture which are needed to derive the correct vertical profile of the 
Bowen ratio in the upper part of the atmospheric boundary layer. As mentioned at the end of section 3.1 the solution of the budget method is very sensitive to the selection of the Bowen ratio profile in heights where turbulent enthalpy and moisture fluxes have different sign and nearly cancel each other.

This paper has looked back at a thirty year period within which Hantel and his co-workers, which had been inspired by him, have developed a powerful and reliable diagnostic tool for regional-scale vertical energy flux profiles out of a global energy budget scheme. A scheme like DIAMOD can serve as an analysis tool to observe and monitor turbulent vertical energy fluxes and convection as well as it can serve as a verification tool for flux parameterisation schemes in regional-scale numerical weather and climate prediction models.

A good knowledge and a full understanding of the vertical turbulent fluxes in the atmosphere is a prerequisite for the assessment of air-surface exchange and regional and global energy budgets. In future, both the development of ground-based remote sensing and of budget methods has to be continued in order to further advance reliable weather and climate prediction techniques. A combination of both methods seems to be a promising approach on an intermediate spatial scale which is within the range of application of both methods.

\section{Acknowledgements}

The measurements west of Munich have been made in the project ICAROS NET (IST-2000-29264) within the $5^{\text {th }}$ Framework Programme of the European Union. The author gratefully acknowledges the suggestions and additions proposed by the two anonymous reviewers and the editor in chief of this journal.

\section{References}

Angevine W.M., S.K. Avery, W.L. Ecklund, D.A. CARTER, 1993a: Fluxes of heat and momentum measured with a boundary-layer wind profiler radar-radio acoustic sounding system. - J. Appl. Meteor. 32, 73-79.

Angevine, W.M., S.K. Avery, G.L. KoK, 1993b: Virtual heat flux measurements from a boundary-layer profiler=RASS compared to aircraft measurements. - J. Appl. Meteor. 32, 1901-1907.

BösEnBERG, J., 2005: Differential-Absorption Lidar for Water Vapor and Temoerature Profiling. In: Weitkamp, C.: Lidar: Range-Resolved Optical Remote Sensing of the Atmosphere. - Springer Heidelberg etc. 213-240.

Denmead, O.T., M.R. RaupaCh, F.X. Dunin, H.A. Cleugh, R. LEuning, 1996: Boundary-layer budgets for regional estimates of scalar fluxes. - Global Change Biol. 2, 255-264.
Denmead, O.T., R. LeUning, D.W.T. GRIFFith, I.M. JAMIE, M.B. ESLER, L.A. HARPER, J.R. FRENEY, 2000: Verifying inventory predictions of animal methane emissions with meteorological measurements. - Bound.-Layer Meteor. 96, 187-209.

EMEIS, S., 1985: Subsynoptic Vertical heat fluxes in the atmosphere over Europe. - Bonner Meteor. Abh. 32, 106 pp. - 1986: Subsynoptic Vertical Energy Fluxes in Midlatitude Cyclones. - Meteorol. Rundsch. 39, 161-172.

—, 2004: Parameterization of turbulent viscosity over orography. - Meteorol. Z. 13, 33-38.

Emeis, S., M. HAnTEL, 1984: ALPEX-Diagnostics: Subsynoptic Heat Fluxes. - Beitr. Phys. Atmos. 57, 495-511.

EMEIS, S., M. TÜRK, 2004: Frequency distributions of the mixing height over an urban area from SODAR data. - Meteorol. Z. 13, 361-367.

ENGElbart, D., J. BANGE, 2002: Determination of boundary-layer parameters using wind profiler/RASS and sodar/RASS in the frame of the LITFASS-project. - Theor. Appl. Climatol. 73, 53-65.

Engelbart, D., M. Kallistratova, R. Kouznetsov, 2007: Determination of the turbulent fluxes of heat and momentum in the ABL by ground-based remote-sensing techniques (a Review). - Meteorol. Z. 16, 325-335.

ERTEL, H., 1942: Der vertikale Turbulenz-Wärmestrom in der Atmosphäre. - Meteorol. Z. 59, 250-253.

ERTEL, K., 2004: Application and development of water vapor DIAL systems. - Dissertation, Univ. Hamburg, Germany. (Available from: www.sub.uni-hamburg.de/opus/ volltexte/2004/2027/)

Fiocco, G., L.D. Smullin, 1963: Detection of Scattering Layers in the Upper Atmosphere /60-140 km/ by Optical RADAR. - Nature 199, 1275-1276.

Giez, A., G. Ehret, R.L. Schwiesow, K.J. DAVies, D.H. LENSCHOW, 1999: Water vapor flux measurements from groundbased vertically pointed water vapor differential absorption and Doppler Lidars. - J. Atmos. Oceanic Technol. 16, 237-250.

Gilman, G.W., H.B. Coxhead, F.H. Willis, 1946: Reflection of sound signals in the troposphere. - J. Acoust. Soc. Amer. 18, 274-283.

GOSSARD, E.E., 1990: Radar Research on the Atmospheric Boundary Layer. In: Atlas, D. (Ed.): Radar in Meteorology. Boston, Amer. Meteorol. Soc. 477-527.

HACKER, J., 1981: Der Massen- und Energiehaushalt der Nordhemisphäre. - Bonner Meteor. Abh. 27, 93 pp.

Haimberger, L., M. HANTEL, 2000: Implementing convection into Lorenz's global cycle. Part II: A new estimate of the conversion rate into kinetic energy. - Tellus, 52A, 75-92.

HANTEL, M., 1976: On the vertical eddy transports in the northern atmosphere. I: Vertical eddy heat transport for summer and winter. - J. Geophys. Res. 81, 1577-1588.

-, 1987: Subsynoptic vertical heat fluxes from highresolution synoptic budgets. - Meteor. Atmos. Phys. 36, 24-44.

Hantel, M., S. EMEIS, 1985: A Diagnostic Model for Synoptic Heat Budgets. - Arch. Met. Geoph. Biocl. A33, 407420.

Hantel, M., M. Steinheimer, 2006: A consistent vertical Bowen ratio profile in the planetary boundary layer. Quart. J. Roy. Meteor. Soc. 132, 2459-2474. 
Hantel, M., L. Haimberger, F. Hamelbeck, 2001: Convection in PIDCAP Part II: DIAMOD - A standard for diagnosing convective quantities. - Meteor. Atmos. Phys. 77, 185-204.

HiRSCH, L., 2002: A Mobile Remote-Sensing System for High-Resolved Wind Vector Profiles and Average Temperature Profiles (SADRASS). - Environ. Sci. Poll. Res. 9, 2734.

Kiemle, C., G. Ehret, A. Giez, K. J. Davis, D. H. LENSCHOW, S. P. ONCLEY, 1997: Estimation of boundarylayer humidity fluxes and statistics from airborne differential absorption lidar (DIAL), BOREAS special issue, - J. Geophys. Res. 102, 29189-29203.

Kouznetsov, R., V.F. Kramar, M. Kallistratova, 2007: The vertical structure of turbulent momentum flux in the lower part of the atmospheric boundary layer. - Meteorol. Z. 16, 367-373.

Linné, H., B. Hennemuth, J. Bösenberg, K. ERTel, 2007: Water vapour flux profiles in the convective boundary layer. Theor. Appl. Climatol. 87, 201-211.

LORENZ, 1967: The Nature and Theory of the General Circulation of the Atmosphere.- WMO-No. 218. TP 115. World Meteorological Organization, Geneva, Switzerland. 161 pp.

Marshall, J.M., A.M. Peterson, A.A. Barnes, 1972: Combined Radar-Acoustic Sounding System. - Appl. Opt. 11, 108-112.

PALMÉn, E., 1966: On the mechanism of the vertical heat flux and generation of kinetic energy in the atmosphere. Tellus 18, 838-845.

PETERS, G., 1991: SODAR - ein akustisches Fernmessverfahren für die untere Atmosphäre. - Promet 21, 55-62.

Peters, G., H. Hinzpeter, G. Baumann, 1985: Measurements of heat flux in the atmospheric boundary layer by sodar and RASS: a first attempt. - Radio Sci. 20, 15551564.

RaO, M.O., S. Casadio, G. Fiocco, M. Cacciani, A.D. SARRA, D. FUA, P. CASTRACANE, 2002: Estimation of atmospheric water vapour flux profiles in the nocturnal unstable urban boundary layer with Doppler sodar and Raman lidar. - Bound.-Layer Meteor. 102, 39-62.

RiEHL, H., J.S. MALKUS, 1958: On the heat balance in the equatorial trough zone. Geophysica 6, 503-538.
SCHMIDT, W., 1921: Wird die Atmosphäre durch Konvektion von der Erdoberfläche her erwärmt? - Meteorol. Z. 38, 262-268.

Schubert, W., E. Ruprecht, R. Hertenstein, R. NiEto Ferreira, R. TAFt, C. Rozoff, P. Cielinski, H.C. KUO, 2004: English translations of twenty-one of Ertel's papers on geophysical fluid dynamics. Meteorol. Z. 13, 527-576.

Seibert, P., F. Beyrich, S.-E. Gryning, S. Joffre, A. RASMussen, P. TERCIER, 2000. Review and intercomparison of operational methods for the determination of the mixing height. - Atmos. Environ. 34, 1001-1027.

SenfF, CH., J. Bösenberg, G. Peters, 1994: Measurement of water-vapor flux profiles in the convective boundary layer with lidar and radar-RASS. - J. Atmos. Ocean. Technol. 11, 85-93.

STULL, R.B., 1988: An introduction to boundary layer meteorology. - Kluwer Acad. Publ., Dordrecht, 666 pp.

TAYLOR, G.I., 1915: Eddy motion in the atmosphere. - Phil. Trans. Roy. Soc. 115 (A 523), 1-26.

UBA, 2007: Nationaler Inventarbericht zum Deutschen Treibhausgasinventar 1990-2005. - Umweltbundesamt, Dessau. Schriftenreihe Climate Change 04/07 (ISSN 1862-4359), 538 pp. (available from www.umweltdaten.de/publikationen/fpdf-1/3239.pdf)

Vogt, S., D. ENGELbART, 2002: Heat flux measurements with a boundary-layer profiler and comparison with other instruments. - Proceed. 11th ISARS, Rome, 343-345.

WulfMEYER, V., 1998: Ground-based differential absorption lidar for water-vapor and temperature profiling: Requirements, development, and specifications of a highperformance laser transmitter. - Appl. Opt. 37, 3804-3824.

— 1999a: Investigation of Turbulent Processes in the Lower Troposphere with Water Vapor DIAL and Radar-RASS. J. Atmos. Sci. 56, 1055-1076.

—, 1999b: Investigations of humidity skewness and variance profiles in the convective boundary layer and comparison of the latter with large eddy simulation results. - J. Atmos. Sci. 56, 1077-1087.

YAnAi, M., S. Esbensen, J.-H. CHu, 1973: Determination of bulk properties of tropical cloud clusters from large-scale heat and moisture budgets. - J. Atmos. Sci. 30, 611-627. 